\title{
Comprehension and E-C Translation of Competence-Related PISA Terms Based on What Kind of People to Be Cultivated
}

\author{
Shen Qunying \\ Department of Pre-college Education, Sichuan Minzu College, Kangding, China
}

Email address:

826666752@qq.com

\section{To cite this article:}

Shen Qunying. Comprehension and E-C Translation of Competence-Related PISA Terms Based on What Kind of People to Be Cultivated. Science Journal of Education. Vol. 6, No. 3, 2018, pp. 76-80. doi: 10.11648/j.sjedu.20180603.11

Received: May 7, 2018; Accepted: May 31, 2018; Published: June 13, 2018

\begin{abstract}
In the era of globalization, informatization and knowledge economy, human talents are the key to social development and global competition. OECD has first formulated their education blueprint on competencies centered on what kind of people to be cultivated. Its PISA2015 Draft Frameworks interweave the terms of competence, competency, literacy, capability, capacity and skill. These education terms confuse people in their interpretation and application, so it is necessary to describe these terms deeply and standardize their translations in pursuit of educational exchange, cooperation among countries.
\end{abstract}

Keywords: Quality, Competence, Competency, Capacity, Capability, Skill

\section{Introduction}

Human talents are crucial to social development and global competition in the twenty-first century with the characteristics of globalization, informalization and knowledge economy. "In order to survive and grow in a changing environment, a society must rely on its members to achieve a certain homogeneous group with common attitudes, value standard, behavioral rules, ideas, etc.", [1] which puts forward new requirements for the cultivation of future human talents. Education shoulders the commands of the society advancement. Human resource is the most important facilitation for social and economic development and global competition. Many international organizations, countries and regions in the world are thinking deeply about how to cultivate future citizens. In order to cater for the current and future technological changes and the demand for globalized talents, some international organizations and countries have built respectively their educational measurement framework of competencies, competences, skills, and the like, highlighting the future talent expectations and propelling educational reform, such as the competencies and key competencies of Organization for Economic Cooperation and Development (OECD), the former key competencies and later key competences of European Union (EU), America's 21st century skills, and Singapore's 21st century competencies [2]. OECD's PISA (program for International Student Assessment) has been particularly popular in recent years. In PISA2015 draft frameworks, the terms of competence, competency, literacy, capability, capacity and skill are interwoven in expression, which confuses people in their interpretation and application. For example, in the parallel texts that I have retrieved, the terms competency and competence are translated as "su yang" or "neng li" in Chinese. Key competencies and key competences are translated as Chinese "he xing su yang" by scholars in Chinese Taiwan, and mostly as "guan jian su yang" or "guan jian neng li" by their counterparts in the mainland China. [3] The terms of competence, competency, skill, capability, and capacity in PISA are generally translated into Chinese "neng li" (i,e., ability) in China. These Chinese translations, either "su yang" or "neng li", result in the difficulties in back translation (retroversion) for they have more than one equivalent in English parallel texts. It is necessary to describe these terms deeply in their concepts, categories and relationship, and to conduct their appropriate translation based on the scientific, monosemy and systematic nature of terminology for the realization of standardized and unified translation, international exchange, mutual reference, and cooperation in education with a convergence of understanding. 


\section{One Chinese "Su Yang", Several English Equivalents}

On September 13, 2016, the Ministry of Education in China put forward Core Competences for Chinese Students' Development (zhong guo xue sheng fa zhan he xin su yang) and clarification of the essential character and key abilities that students should have to adapt to the needs of individual lifelong and social development. By means of translation method of looking for equivalent [4] based on English parallel corpora, such English equivalents as competence, competency and literacy can be found for Chinese term "su yang", and such words as competency, competence, and literacy are often used interchangeably to express knowledge, skills and attitudes applied appropriately to contexts. Based on Chinese parallel texts, these words can be found with the same Chinese "su yang" [5] equivalent.

\subsection{Detailed Description of Competence and Competency}

Competence means the state or quality of being adequately or well qualified, a specific range of skill, knowledge, or ability; [6] competence is competency, the ability to do what is needed, a satisfactory but not unusual degree of skill. [7] As they are much alike in definition, some scholars at home and abroad think that the items of competency and competence have the same meaning and can be used alternately without the need to make a distinction between them, [8] that competency and competence can both be translated as "su yang" in Chinese with no need to argue further, [9] except that the American authors often prefer competency and competencies, and the British authors prefer competence and competences.

However, others see the differences between the two terms. For example, Klemp believes that competence is a kind of underlying characteristic of a person to achieve effective and extraordinary performance at work, and a state or comprehensive quality of individuals that makes the work efficient or excellent; while competency is the feature that has something direct to do with the efficient or excellent working performance of specific scenarios. [10] Spencer and other scholars argue that competence is a collection of related factors including knowledge, attitudes and skills; while competency is a potential, in-depth feature in specific work, including motivation, traits, self-image, attitudes and values, knowledge and cognitive or behavioral skills of a certain field - any individual characteristic that can be measured and assessed on its excellent or general performance. [11] In my opinion, the two terms are different, but interrelated. The term competence is a functional concept, which relates to outcome and performance from interaction between situations and integration of knowledge, abilities and attitudes. It refers to the potential qualities that people have after being educated and trained, and it can lead to and have an effect on better and more effective individual performance. It is a collection of related knowledge, skills, abilities, moral characters, attitudes, and so on, which enable a person or an organization to act effectively in a job or a situation.
The other term competency, which exists in relation to behaviors, involves the ability to meet complex demands, by drawing on and mobilizing psychosocial resources (including knowledge, skills, attitudes and others) in a given situation, explicitly represents the individual characteristics in competence that are directly related to activities and playing a functional role in evidence-based practice. In essence, competency is demand-oriented, behavioral characteristics resulting in successful performance, and it is generated out of the effective interaction between the individual and the situation. It shows not all the characteristics in competence, but parts that can help distinguish good performances from bad ones, that is, a set of observable and measurable behaviors in a task or a scenario. Obviously, the relationship between competence and competency can be regarded as a collection and its element. Therefore, they do well to be respectively translated as "su yang" and "xiao su" in Chinese. In terms of the transparency and systematicness of related terms in semantics, "su yang" as the Chinese translation of competence is a combination of "su zhi" (quality-oriented) and "yang yu" (nurture and cultivation), which embodies the people-centered education and training philosophy and implies its super ordinate concept of "quality", which shows the situation and process of competence - the combination of innate predisposition and the acquired education, learning, and cultivation in the context of social, family, school education, and which highlights the abundance of its content involving knowledge, skills, abilities, attitudes and personality, and which suggests that competence can be teachable, learnable, and cultivable. In addition, the term competency, which is an abstract noun with the suffix "-y," implies a tendency to competence in a reasonable attribute, status, condition, and behavior, which can infer its super ordinate concept of "competence." Just as its Chinese name "xiao su" (effective attainment) implies, competency refers to a certain competence representation of achieving concrete effective results, and even acts as the performance outlet and the input source to enrich competence [12], and it is competence-oriented.

\subsection{Deep Description of Literacy}

Literacy is another English equivalent of Chinese term "su yang". Based on dict.cn.ki.net, the word literacy is translated as "su yang" (competence) for 1526 times, "su zhi" (quality) 768 times, "shi zi" (learning to read) 95 times, "du xie neng li" (the ability to read and write) 14 times, and "wen hua" (culture) twice. In addition, the termonline.cn shows that the relevant terms such as scientific literacy, technical literacy, and information literacy are usually translated respectively as "ke xue su yang," "ji shu su yang" and "xin xi su yang" in Chinese, where the word literacy is obviously the equivalent of "su yang".

The term literacy originally refers to the ability to read, write, count and express, and is simply defined as the set of technical skills of reading, writing and calculating. In such expressions as literacy school, literacy education system, literacy education system, and International Literacy Day, the term literacy is often translated as "sao mang" (eradication of illiteracy) or "tuo mang" (out of illiteracy), whereas its 
opposite illiteracy is often translated as "wen mang" in Chinese. Literacy and illiteracy are divided based on literacy rate, which suggests the basic level of literacy in individual education accomplishment. And it is later incorporated by United Nations Educational, Scientific and Cultural Organization (UNESCO) into the Universal Declaration of Human Rights as a right to education with the definition of "the ability to identify, understand, interpret, create, communicate and compute, using printed and written materials associated with varying contexts. Literacy involves a continuum of learning to enable an individual to achieve his or her goals, to develop his or her knowledge and potentials, and to participate fully in communities and the wider society". [13] Literacy is an essential component of basic quality education in laying the basis for individual lifelong development. With the development of globalization and the advancement of information and communication technologies, the term literacy is often used to designate basic competencies in domains other than those immediately concerned with written texts, such as computer literacy, media literacy, health literacy, eco-literacy, emotional literacy, and the like. Apparently, the meaning of literacy has become extremely complicated and multi-dimensional, referring to not only various skills based on reading and writing, but also the social practices by using alphabets, languages, numbers, images, sounds, movies, three- dimensional animation and other symbol systems, together with computer, communications, network and other basic means to understand, communicate and obtain useful knowledge and corresponding technologies [14]. Acquisition and application of literacy lays the foundation for individual further sustainable development. Literacy acting as the basis of competency and competence, its connotation is fully described in the PISA2015 Draft Frameworks. Literacy, which has the suffix "-y," is an abstract noun with the development tendency to the ultimate competence. Thus, it can be translated as Chinese "ji su" which means basic competence and indicates the basic and higher level relationship between literacy and competence.

Compared with competency and literacy in the same system, competence is a concept of higher level, and competency is the external manifestation of the individual characteristics in competence on the basis of literacy in practice, and literacy is the basic component of competence embodied in competency in practice. That is to say, competence is the-upper-level and holistic concept, which can be translated as Chinese "su yang"; whereas literacy is a lower-level term, which can be translated as "ji su" (basic competence); and competency is a middle-level term, which can be translated as "xiao su" (effective attainment).

\section{Same Translation as "Neng Li" in Chinese, Different Concepts in English}

In PISA2015 Draft Frameworks, there are five terms of competence, competency, capacity, capability, and skill.
Chinese domestic scholars always translate them into the same Chinese phrase "neng li" (ability), which leads to the difficulty in English back translation. Although these terms have close relations in human talents' measurement, they have different connotations.

\subsection{Competence and Competency}

Competence is a semantic complex concept, not only signifies knowledge and skill, but also includes the ability to utilize all sorts of social mentality (feelings and attitudes) to satisfy complex needs. Competence has more extensive connotations than ability. The former is generated from long-term design and cultivation of human education, i.e. competence is teachable and learnable. The latter ability can be inborn or acquired through the learning. Obviously, it narrows its signification that "neng li" (ability) acts as the Chinese equivalent of competence.

Competency is a mixture of knowledge, skills, abilities, motivations, beliefs, values and interests in a specific practice context. It is the behavioral dimension of the word competence, which has cause-and-effect relationship with performance excellence in a specific context. It can be regarded as the specific application of competence's effective characteristics based on literacy in specific context. "neng li" as the Chinese equivalent of competency also narrows its signification.

According to the above description of competence and competency, they have more extensive connotations than ability, and they are in whole-part relation, so the terms of competence and competency had better be translated respectively into Chinese "su yang" and "xiao su" instead of "neng li".

\subsection{Deep Description of Capacity and Capability}

Chinese "neng li" is the regulated translation of capacity on termonline.cn, such as learning capacity (xue xi neng li), teacher's professional capacity (jiao shi de zhi ye neng li), debt capacity (ju zhai neng li), administrative capacity (guan li neng li), innovative capacity (chuang xin neng li), government capacity (zheng fu neng li). According to http://www.dict.cn/, capacity means the power to hold, receive, absorb or accommodate, i.e. the amount that can be contained. Used for people, capacity refers to the power to learn or retain knowledge. In essence, capacity implies the internal potential ability of a person, usually not physical strength but intelligence, especially the maximum mental ability in acceptance, comprehension, tolerance, and execution, as well as the potential energy of specific functions and authority to perform. For example, memory capacity means the amount people can remember, and transmission capacity implies the amount to transmit. The term capacity had better be translated into Chinese "neng xian" (power limit) instead of "neng li".

Likewise, "neng li" is also the regulated Chinese translation of capability on termonline.cn, such as assimilate capability (xi shou neng li), innovation capability (chuang xin neng li), recovery capability (hui fu neng li), and shared 
capabilities (tong yong neng li). The term capability was adopted in British Education for Capability Manifesto in 1980 and The Higher Education for Capability Initiative in 1988. Capability is usually defined as a feature of being capable of something, which is essentially a practical ability to engage in a certain activity or achieve a certain purpose, and to solve practical problems [15]. It describes the ability of the individual to apply knowledge and expertise in practice, to perceive, think, and operate based on the capacity of the human being. Capability is a collaborative process where people are able to evaluate, apply, develop, transmit knowledge and skills stored and accumulated in competence [16], that is, through which individual competences can be applied and exploited. Capability is accompanied by enterprise, it signifies the higher-level ability that an individual can achieve, improve, or integrate the capacity and the expertise of the individual to go further. Capability implies the abilities which are not yet developed, and it can be developed in practice as professional competency. Competency is distinguished characteristics of good performances, resulting from capability applied in practice on the basis of capacity. Capability may just as well be translated into Chinese "cai neng", "cai" means the knowledge or experience that has been stored, yet not utilized. "neng" means potentiality. "cai neng" means the knowledge, experience, physical strength and intelligence that a person already possesses, but hasn't yet performed.

The term skill can be seen in American Partnership For 21st Century Skills (2002) and Better Skills, Better Jobs, Better Lives: A Strategic Approach to Skills Policies issued by OECD in 2012. In English, skill means the ability to fulfill tasks and solve problems by applying knowledge and utilizing know-how skill. This ability to do things is gained through practical operation and training. In essence, it is the visible ability in a specific practice task [17]. According to CNKI translation assistant, skill is translated into Chinese "ji neng" for 3780 times, "ji shu" 2657 times, "ji qiao" 2000 times, "ji fa" 147 times, or "ji yi" 87 times. In addition, "ji neng" is the regulated Chinese translation of skill on the termonline.cn, such as language skills (yu yan ji neng), job skill (gang wei ji neng), generic skill (tong yong ji neng), skill training (ji neng xun lian), so I prefer the Chinese translation "ji neng" for skill.

\section{Conclusion}

Education is a kind of activity that imparts certain values, cultural rules, living and production skills as well as knowledge to facilitate the socialization of people. Receiving education is human being's basic rights and fundamental need of survival and development. It aims essentially to gain knowledge and skill, to develop kinds of literacy, capacity and capability, to gradually form sorts of competence, and even to achieve the quality of individual or social expectations. The boom of key competences in the worldwide is essentially the upgraded movement of the educational quality and the main reflection of the international competition in education. By means of relative terms in PISA 2015 Draft Frameworks, the relations among quality, competence and other relevant concepts are constructed in figure 1 as follows:

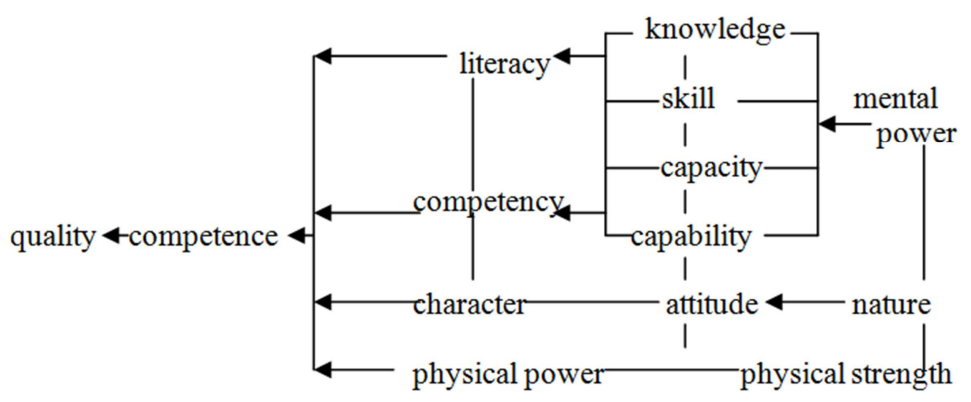

Figure 1. Relation among quality, competence and other involved terms.

Obviously quality and competence are hypernyms with rich connotations, and they are comprehensive collection of knowledge, skill, ability and individual character stored by people, consisting of steady knowledge, skill, literacy, competency, capacity, capability, attitude, character and physical power that people possess. Quality is a relatively static super-ordinate concept, referring to a relatively stable character or outcome formed in long-term physical and mental accumulation and development on the basis of predisposition (human nature, mental power, and physical strength). It is the ultimate result of competence. Competence is a relatively dynamic concept with dependence on the specific situation. Through cultivation, training and practice, individuals gain knowledge, skill, ability, attitude and strength in physical body and mentality. It is the prerequisite or source of quality in reality. Only when competence becomes stable and essential in people's mind and body can it become quality. Competence is a complex structure that integrates knowledge with skill, cognition with emotion, creativity with character. Literacy refers to basic competence such as disciplinary knowledge, reading and writing ability, practical skill and ability, as well as competency. Competency is composed of learned skill, acquired knowledge as well as capacity and capability in developed behavior. Capacity is the utmost ability and extreme instinct that are inborn and are capable of receiving, perceiving and doing things. Capability is the extreme of ability that is used to fulfill objectives or tasks based on capacity. It is the application and manifestation of competencies. Skill is the ability to use knowledge and experience to carry out certain 
activities, in which proficiency can be perceived.

Above all, there are differences among these terms of skill, literacy, capacity, capability, competency, competence and quality. Therefore, when we introduce them in China, we had better translate them respectively into Chinese correspondence "ji neng", "ji su”, "neng xian", "cai neng", "xiao su", "su yang", and "su zhi" to show their different reference, which can avoid ambiguity "suyang" or "nengli" in quotation terms, and meanwhile manifest the category and relationship among these terms. Knowledge is the basis of skills; knowledge and skills develop literacy, and they are the basic elements of abilities. Only generalized knowledge and proficient skill can be widely applied and transferred into real abilities in capacity, capability, competency, competence and quality. And ability itself is the internalization of knowledge and skill. In turn, ability influences the grasp of knowledge and skill. The implication of competence is broader, it is complex, advanced, integrated and humanized storage and accumulation of knowledge and skill. It is also the improvement of character and ability as well as the formation and development of intelligence, emotion and morality in the real context. Only in real context can knowledge be created, skills be practiced, abilities be improved, character be elevated, competences be developed [18] and quality be enhanced.

\section{References}

[1] B. Davies, Social Control and Education, London: Methuen, 1976, p. 30

[2] Singapore Ministry of Education. 1998. 21st Century Competencies [R]. Singapore: Ministry of Education.

[3] Pei Xinyu and Liu Xinyang, Reconstructing Education for the $21^{\text {st }}$ Century: The Establishment of the "Core Qualities" Framework in the European Union, Global Education Prospect, vol. 12, 2013, p. 96.

[4] Li Yashu and Xu Shude, On Translation Method of Looking for Equivalents of Term. Journal of China Terminology. Vol. 18, No. 3, 2016, p35.

[5] Lin Chongde, Twenty-first Century Core Competencies of Students' development research. Beijing: Beijing Normal University Press, 2016, p. 57.
[6] American Heritage Dictionary. American Heritage Dictionary of the English Language, 2006 (4th ed.). [2018-02-11]. $\mathrm{http}: / /$ dictionary.reference.com/search?q=competence.

[7] Zhao Yaming, Longman Contemporary English- Chinese Dictionary. Beijing: Modern Press, 1988, p. 282

[8] V. Joke, and P. R. Natalie, A Comparative Analysis of International Frameworks for 21st Century Competences: Implications for International Curriculum Policies. Journal of Curriculum Studies, No. 3, 2012, p. 299-321.

[9] Chu Hongqi, The International Perspective and China's Stance of Key Competencies-The Enhancement of National Qualities and the Transformation of Educational Goals in 21st Century in China, Education Research, No. 11, 2016, p. 8.

[10] G. O. Klemp, The Assessment of Occupational Competence. Washington, DC.: Report to the National Institute of Education. 1980, p. 21.

[11] L. M. Spencer, D. C. McClelland and S. Spencer, Competency assessment methods: History and state of the art. Boston: Hay-McBer Research Press, 1994, p. 14.

[12] W. E. Doll, Developing Competence. In Doll, W. E. Pragmatism, Post-Modernism, and Complexity Theory. Edited by Donna Trueit. New York: Routledge, 2012, p. 67.

[13] UNESCO. The Plurality of Literacy and Its Im- plications for Policies and Programmes. (PDF). UNESCO Education Sector Position Paper. Paris: UNESCO, 2004, p. 13.

[14] The New London Group. A pedagogy of multiliteracies: Designing social futures. In Cope, B. \& Kalantzis, M. (eds). Multiliteracies: Literacy Learning and the Design of Social Futures. South Yarra: Macmillan, 2000, p. 38.

[15] Hu Tiesheng and Ma Shuzhi, The Focuses of Ability, Capacity, and Capability, College English, No. 7, 1996, p. 63.

[16] Leonard. Barton. D. Wellsprings of Knowledge: Building and Sustaining the Sources of Innovation. Boston. MA: Harvard Business School Press, 1995.

[17] Jean Gordon et al., Key competences in Europe: Opening Doors for Lifelong Learners Across the School Curriculum and Teacher Education. Case Network Reports, Vol. 87, 2009, p. 39.

[18] Feng Zhongliang, Structure: A Report on Targeted Teaching Experiment, Journal of Beijing Normal University, 1992, p. 100. 